\title{
Concepción y dinámica familiar: Análisis desde la percepción de un grupo de niños de cuatro años
}

\author{
Conception and family dynamics: \\ Analysis from the perception of a group of four-year-old
}

DOI: http://dx.doi.org/10.17981/cultedusoc.10.2.2019.05

Recibido: 07//2019 Aceptado: 13/09/2019

Yesid José Ortega Pacheco

Universidad del Magdalena (Colombia) yesid.1594@gmail.com

Michael Hernández Bolívar

Fundación Universitaria Claretiana (Colombia)

michaelhdez19@gmail.com

\author{
Virginia Isabel Barrero Toncel \\ Universidad del Magdalena (Colombia) \\ vibarreto4@gmail.com
}

Para citar este artículo:

Ortega, Y., Hernández, M. y Barrero, V. (2019). Concepción y dinámica familiar: Análisis desde la percepción de un grupo de niños de cuatro años. Cultura, Educación y Sociedad, 10(2). 63-72. DOI: http://dx.doi.org/10.17981/cultedusoc.10.2.2019.05

\section{Resumen}

Con el objetivo de analizar la percepción de un grupo de niños de 4 años de edad acerca de la concepción y dinámica familiar en Colombia, se realiza una investigación de enfoque cualitativo con diseño fenomenológico. Se trabaja con 35 niños pertenecientes a los estratos socioeconómicos 1 y 2 catalogados como de bajos recursos por parte del Sistema de Selección de Beneficiarios para Programas Sociales (SISBEN). La recolección de la información se hace a través de la entrevista semiestructurada; así mismo se diseñan 14 representaciones ilustrativas animadas, como técnica de estímulo visual, con diferentes miembros posibles de un grupo familiar. Los resultados muestran que el concepto de familia para los niños y niñas está basado en sus propias apreciaciones relacionadas con el estilo de apego y crianza que poseen. Por otra parte, se evidencia que la dinámica familiar es un factor determinante para que estos expresen percepciones positivas o negativas de su hogar y sus familiares.

Palabras clave: Percepción; concepción de familia; dinámica familiar; niños

\section{Abstract}

In order to analyze the perception of a group of 4-yearold children about family conception and dynamics in Colombia, a qualitative approach research with phenomenological design is carried out. It works with 35 children belonging to socioeconomic strata 1 and 2 catalogued as low resources by the System for the Selection of Beneficiaries for Social Programs (SISBEN). The collection of information is done through the semi-structured interview; likewise, 14 illustrative animated representations are designed, as a visual stimulus technique, with different possible members of a family group. The results show that the concept of family for children is based on their own appraisals related to the style of attachment and upbringing they possess. On the other hand, it is evident that family dynamics is a determining factor for these children to express positive or negative perceptions of their home and family members.

Keywords: Perception; family conception; family dynamics; children 


\section{INTRODUCCIÓN}

A lo largo de la historia, el ser humano ha sido consiente de las innumerables transformaciones que ha presentado la sociedad y con ello, la incidencia que ésta ha tenido en el desarrollo familiar, dado los incalculables cambios a los que se ha visto expuesta (Abril y Peinado, 2018). La familia ha dejado de ser imaginada como la unión de una pareja heterosexual para dar lugar a nuevos conceptos y definiciones apoyadas por las modificaciones que ha tenido que enfrentar ante la llegada del nuevo siglo (Salgar, 2017). Anteriormente, el concepto global de familia estaba representado solamente por el padre, la madre y los hijos (Oliva y Villa, 2014), en la actualidad, existen nuevas formas de comprender qué es una familia, lo que implica necesariamente evolucionar en la manera de analizar y estudiar este grupo de la sociedad, teniendo en cuenta que su definición se construye más allá de las experiencias personales que viven los sujetos que hacen parte de esta (Alegre, 2015). Se infiere que la concepción de familia va asociada a estadios de realización personal y social. Ferrel et al (2014), destacan que una sociedad conformada por individuos satisfechos, generan emociones positivas contribuyendo a desarrollar instituciones sólidas, tal es el caso de la concepción familiar, como organización de carácter formal.

Desde la psicología evolutiva, el termino familia es concebido como la relación de unión existente entre un grupo de personas que comparten un proyecto de vida en común y que llega a ser duradero en el tiempo, así mismo, los sujetos involucrados poseen un compromiso personal y sentimientos de pertenencia a éste, estableciendo relaciones intensas de reciprocidad, dependencia e intimidad (Rodrigo y Palacios, 2012). Por ello, la nueva comprensión de la familia como ente básico de la sociedad no se reduce a relaciones de carácter biológico, sino que implica la inclusión de diferentes elementos relacionados con la percepción que tiene el sujeto desde su experiencia como miembro de lo que es para él una familia, es decir, debe considerarse la integración de nuevos conceptos como las uniones maritales de hecho o integrados por personas del mismo sexo, siempre que se encuentren unidos por los lazos descritos y tengan los fines de convivencia y solidaridad invariables (Oliva y Villa, 2014).

Desde la infancia, la familia se constituye como uno de los primeros agentes que ejerce gran impacto e influencia en función del desarrollo de los niños en términos de cuidado, educación, protección y afecto (Infante y Martínez, 2016); la familia no sólo debe garantizar condiciones económicas para hacer posible su desempeño escolar y prepararlos desde su nacimiento, para que puedan participar, aprender y convivir activamente en comunidad (Espitia y Montes, 2009), además de cumplir funciones generales de hospitalidad, vinculación y reconocimiento que permitan la evolución óptima e integral de estos (Páez-Martínez, 2016), así como también contribuir con el desarrollo biosicosocial del individuo, teniendo en cuenta su influencia sobre el sujeto (Rigg y Pryor, 2007).

Según los estudios de Anyan \& Pryor (2002), el concepto de familia que tiene el niño pequeño gira en torno a la convivencia y el contacto, mientras que los factores biológicos y legales se presentaban con mayor frecuencia en las descripciones de los participantes de mayor edad (Anyan y Pryor, 2002). Al respecto, Mena y Huneeus (2017) destacan que la convivencia, incluida el núcleo familiar, resulta un factor clave que contribuye al desarrollo socioafectivo y éti- 
ca de cada uno de sus miembros. Para Rigg y Pryor (2007), independientemente de la estructura familiar en la que el niño se encuentre inmerso, su percepción sobre la familia siempre va a ser la misma, ya que posee factores afectivos que determinan su concepto (Rigg y Pryor, 2007).

Cabe destacar como en décadas anteriores a la actual, las investigaciones con niños desde un enfoque cualitativo eran escasas puesto que le agregaban poco valor considerable a su discurso. Sin embargo, hasta la fecha, los estudios bajo las ciencias sociales consideran a este tipo de población como sujetos capaces de representar las relaciones sociales, así como la habilidad que tienen para actuar en la transformación del mundo infantil y los pensamientos sociales existentes (Vergara, Peña, Chávez y Vergara, 2015).

Del mismo modo, la psicología cognitiva plantea la noción de representación mental para comprender cómo las personas registran, en una especie de memoria interna, las experiencias del mundo externo y así construir conceptos, imágenes, esquemas y modelos mentales para abordar el problema del conocimiento y los procesos cognitivos que la subyacen (Perinat, 2007; Rodrigo y Correa, 2003). Para referirse a la función simbólica o semiótica, Piaget e Inhelder (2007) afirman que ésta surge al término del periodo sensoriomotor y permite simbolizar objetos y acontecimientos por medio de un significante diferenciado como el lenguaje, la imagen mental o el gesto simbólico, lo cual resulta particular o exclusivo para tal representación mostrando que la habilidad de personificar y construir imágenes mentales permite desarrollar el pensamiento de manera más elaborada (Piaget e Inhelder, 2007).

Esta capacidad cognitiva del niño para representar cualquier aspecto del mundo exterior implica que son capaces de construir ideas sobre las realidades del orden social, aunque sus representaciones difieren de los adultos, respondiendo con las explicaciones que son capaces de formular tanto desde su nivel de desarrollo, calidad y cantidad de información que reciben como desde su experiencia personal.

En este sentido, las definiciones de los niños y niñas no son teorías elaboradas y complejas, sin embargo, no dejan de ser teorías validas al momento de comprender muchos fenómenos sociales (Parra, 2010). Es por esto que los nuevos estudios sociales conciben a los niños y niñas como agentes sociales y destacan tanto sus capacidades de comprender el mundo desde su propia percepción. En tal sentido, los niños se constituyen tempranamente como sujetos de derecho plenamente sociales y políticos (Jaramillo, 2007; Vergara, Peña, Chávez y Vergara, 2015). Desde este punto de vista, el objetivo del presente estudio es analizar la percepción de un grupo de niños de 4 años de edad acerca de la concepción y dinámica familiar en Colombia

\section{Metodología}

El estudio se enmarca en el enfoque de investigación cualitativa que busca comprender los fenómenos en su espacio natural, puesto que permite describir las situaciones o hechos basados en la experiencia y el sentido que le dan los sujetos inmersos en ellos (Cuenya y Ruetti, 2010), lo que da lugar a conocer los diferentes puntos de vistas y significados que le otorgan a sus vivencias (Hernández, Fernández y Babtista, 2014). El diseño metodológico se basa en los lineamientos de la fenomenología donde se comprenden y describen los fenómenos de la conciencia y la realidad subjetiva, es decir, busca dar significado a 
los acontecimientos que rodean al ser humano en su vida (Martínez, 2011; Loreto y Pinilla, 2017).

El grupo de interés para la investigación lo conforman 120 niños y niñas de estrato socioeconómico 1 y 2 que hacen parte del Sistema de Selección de Beneficiarios para Programas Sociales (SISBEN), catalogados como bajos recursos, que asisten a servicios de guardería comunitaria. Específicamente, se trabaja con 35 infantes de los cuales 15 eran niños y 20 niñas. El grupo de interés se conforma según criterios de conveniencia de los investigadores en atención a sus características similares, proximidad y accesibilidad (Salkind, 1998; Casal y Mateu, 2003; Otzen y Manterola, 2017). Como técnicas de recolección de información se implementó la entrevista semi estructurada, la cual consiste realizar en una serie de preguntas previamente elaboradas por los investigadores que son presentadas a los sujetos de estudio, caracterizándose por la flexibilidad al momento de aclarar términos, identificar ambigüedades y reducir formalismos que permitan a su vez realizar preguntas complementarias con la finalidad de ampliar la información y contribuir a la consecución del objetivo de estudio (Díaz-Bravo, Torruco-García, Martínez-Hernández y VarelaRuiz, 2013).

Para efectos de la investigación, se diseñan 14 representaciones ilustrativas animadas con diferentes miembros posibles de una familia como técnica de estímulo visual (Moscoso y Díaz, 2017) que permite a los participantes explicar a través de las imágenes sus propias ideas (Miller, 2015). Además, este tipo de representación permite a los niños y niñas expresar fácilmente sus percepciones y logra evitar que se sientan presionados al hablar de ellos mismos o de otro tipo de situaciones (Gómez, 2012).
Posteriormente, se aplica el análisis de contenido como "metodología sistemática y objetivada porque utiliza procedimientos, variables y categorías que responden a diseños de estudio y criterios de análisis, definidos y explícitos" (Bernete, 2013, p. 222). El análisis de contenido, a decir de Marín (2012), representa una técnica de investigación que permite develar el tratamiento teórico que un autor hace de un determinado texto, evidenciado en categorías emergentes. Igualmente, se utilizó el software Atlas Ti como técnica la comprensión de los datos suministrados por los participantes permitiendo la codificación, categorización y el respectivo análisis de los datos encontrados (Varguillas, 2006; San Martín, 2014).

La investigación considera los procedimientos éticos pertinentes como la utilización del consentimiento informado, donde los acudientes de los sujetos de estudio aceptan su participación en la investigación realizada. Esto se apoya en el marco legal propuesto por la Ley 1090 (2006, art. 52) por la cual se reglamenta el ejercicio de la profesión de psicología, se dicta el Código Deontológico y Bioético y otras disposiciones.

\section{Resultados}

Los resultados se organizan en tres categorías de análisis:

1. Conocimiento general de la familia.

2. Relaciones familiares.

3. Percepción de mi familia.

\section{Conocimiento general de la familia}

En esta categoría se expone cuáles son las ideas que tienen los niños y niñas sobre qué es la familia, donde se observa qué 
conocen acerca de cómo está compuesta y quienes hacen parte de ella, así mismo expresan un gran número de definiciones basadas en su propio aprendizaje sobre la familia en Colombia. Esto puede estar relacionado con lo aprendido dentro de la escuela donde asisten, debido a la enseñanza impartida por sus maestras o por la formación recibida en el hogar proveniente del aprendizaje cultural y social del contexto en donde se desenvuelven. Es por esto que señalan:

"Ay profe... el papá y la mamá" (S1).

"La familia son los papás...

así como yo vivo..." (S5).

"Mamá, papá, hermanos" (S9).

“Mamá, papá, tía y abuela” (S18).

“... son pues la mamá, el papá,

los hermanos...todos" (S21).

“Mamá, papá, abuela y hermanos” (S25).

“.. la mamá, el papá y los hermanos” (S30).

"Mi familia es mi mamá, mi papá, mis hermanos, mis abuelos,

tíos y primos, profe" (S34).

A partir de esto, se observa que los sujetos de estudio tienen una noción general sobre cómo puede estar conformada una familia, esto independientemente de cómo pueda estar formada la suya. Por tal motivo, son capaces de entender e interpretar la pregunta de investigación dando una respuesta clara con relación al objetivo planteado.

\section{Relaciones familiares}

En este apartado los niños y las niñas dan a conocer quienes conforman su familia basados en las personas que conviven dentro del mismo hogar, lo cual, para los menores está intrínsecamente relacionado con los miembros a los que comparten diariamente sus rutinas y hábitos, dando repuesta al interrogante sobre quienes forman su familia. A esto aluden:

"Mi papá, mi mamá y mi hermano" (S2).

“... mis papás... también tengo otros que viven en otras casa" (S5).

"Mi mamá y mi abuela" (S6).

“... papá, mamá y mi hermano” (S14).

"Vivo con mi mamá, mi hermana y mi papá" (S22).

“... mi mamá, mi tía, mi primo, mi abuela, mi abuelo y yo profe” (S28).

"Mi mamá porfe..." (S31).

“Mi papá y mi mamá” (S35).

Esta categoría muestra como los niños y las niñas reconocen de su contexto a los diferentes miembros que hacen parte de su familia, bien sea por contacto permanente o por enseñanza previa de algún otro familiar, por lo que tienen conciencia de ello y los reconocen como tal.

Para el desarrollo de la categoría percepción, se les pidió a los niños y niñas que armaran su familia a través de las representaciones ilustrativas animadas orientados por la pregunta: ¿quiénes son tu familia/ qué es la familia para ti?, lo cual previamente se les explicó con la función que tenía la actividad, así mismo, cada ilustración y su significado. Además, se le enfatizó que estos eran libres escoger todas las que quisieran y las colocaran en la posición que desearan. Luego de esto, se les preguntó el motivo por el cual habían tomado esas ilustraciones en particular. Gracias a este estimulo visual los participantes lograron explicar los significados atribuidos basados en sus propias ideas. 
En esta categoría se observa la diferencia de conceptos que tienen los niños y las niñas sobre la familia de manera general, a quienes reconocen como miembros de ella y qué es familia para ellos, orientados en lo que experimentan y sienten. Por otra parte, se evidencia que independientemente de su corta edad, lograron entender y dar respuesta a cada uno de los interrogantes planteados a lo largo de proceso investigativo.

\section{Percepción de mi familia}

Esta categoría da a conocer como independientemente de las personas con las cuales viven los niños y niñas y comparten no solo el día a día en su hogar, sino también otro tipo de actividades, desde su propia percepción no los conciben propiamente como su familia. Por el contrario, son vistos como sujetos parte de ella, pero que no alcanzan a otorgarles la misma cantidad de valor emocional como a los otros que llegan a sentir más cercanos sin importar que sean madre o padre, por ello, aluden lo siguiente:

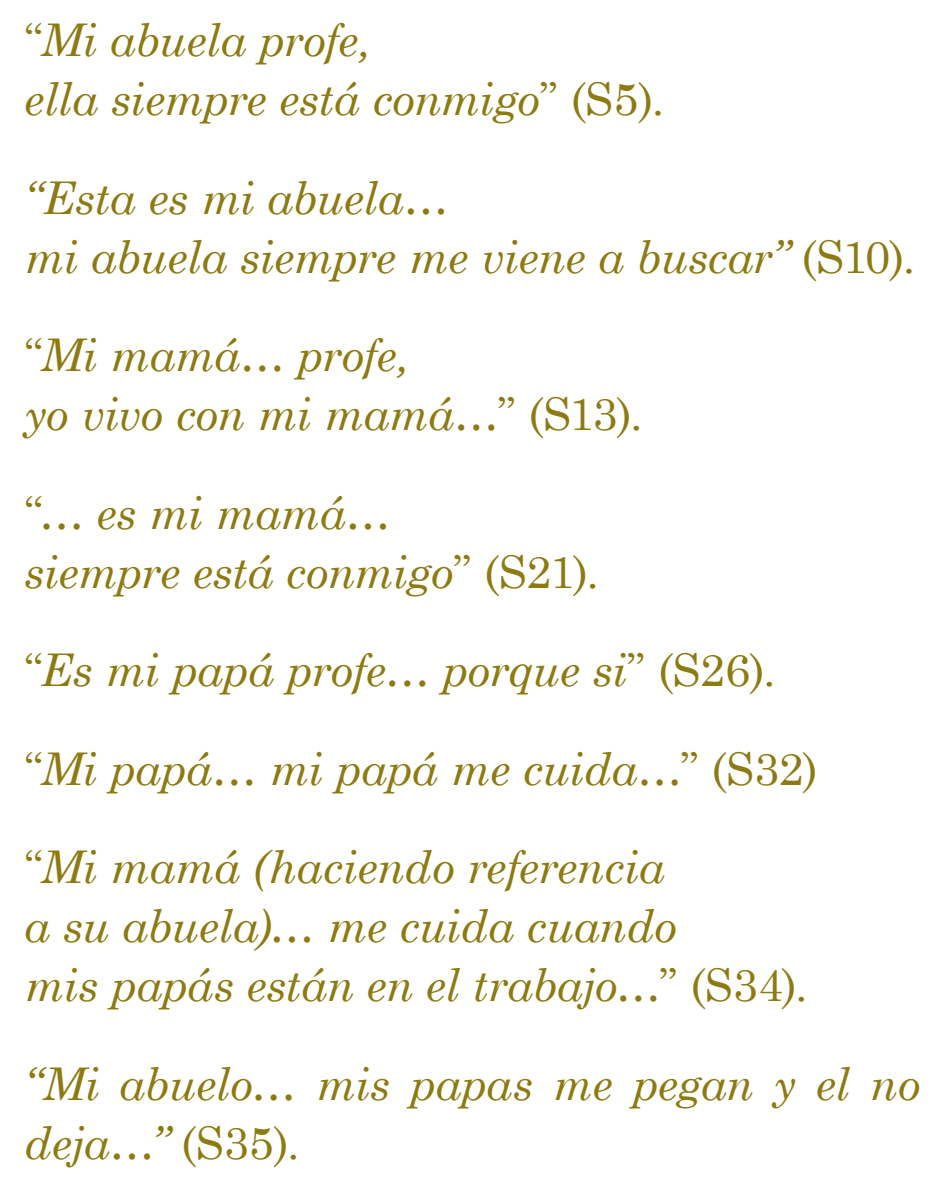

\section{DisCUSIÓN}

La familia es concebida como la organización social que le da sentido y fuerza a sus integrantes, siendo ésta la que los une y los coloca en estrecho contacto con el mundo exterior (Sánchez, 2012). Los niños y niñas a pesar de su corta edad conocen el concepto de lo que es en teoría la familia y reconocen la forma en como está organizada. Por tal motivo, le atribuyen un rol específico. Además, aunque la mayoría no está en relación constante con familiares que no pertenecen directamente a su núcleo primario, ellos son conscientes que hacen parte de la conformación de su familia (Triana, Ávila y Malagón, 2010; López y Guiamaro, 2016).

Para Gallego (2012), la percepción que existe del concepto de familia suele ser muy ambiguo y principalmente subjetivo, lo cual, claramente está sujeto a múltiples variables externas e internas que pueden moldear la imagen que los niños y niñas tengan de los miembros de su familia $\mathrm{y}$ consecuentemente de sí mismo. La autora expresa que existen tres aspectos básicos a la hora de entender las percepciones que puedan tener cada uno de los miembros del hogar. El primero de éstos da lugar a la familia como organización que cambia y que dichos cambios están relacionados al periodo histórico y social de cada época; el segundo hace referencia al proceso de socialización primario dentro del grupo familiar, donde los hijos e hijas se deben comportar con base en los requerimientos del contexto; y el tercero, toda familia posee su propia dinámica interna y externa (Gallego, 2012).

De acuerdo con Acevedo (2011), existen siete tipos de familias, en un primer orden la familia nuclear o completa; seguida por la familia fruto de relaciones de hecho; la 
familia fruto de la unión libre; familia de madre soltera; familia extensa o consanguínea; familia monoparental y la familia sin vínculos, para el autor esta última no es propiamente una familia porque no comparte lazos de consanguinidad, sino que comparten vivienda por motivos económicos. En contraste con los hallazgos de la investigación, se puede apreciar como dentro del relato de los niños y niñas no existe un tipo de familia que domine frente a las demás formas, es decir, la familia tradicional conformada por padre y madre no muestra una gran ventaja frente a la familias monoparentales o las familias extensas, ya que, generalmente provienen de hogares que se formaron de algunas de las modalidades de familias mencionadas anteriormente (Acevedo, 2011).

Al observar las respuestas de los niños sobre qué es la familia para ellos, a través de las representaciones ilustrativas animadas se aprecia en sus respuestas, en primer lugar a la persona que resulta ser más importante y significativa, y con las que comparten más tiempo en su crianza; la conciben como su familia principal, basado en sus propias percepciones gracias a la creación de figuras subsidiarias, que se dan por la interacción permanente de los niños con alguna persona adulta responsable sinónimo de seguridad familiar. No obstante, esto no quiere decir que no existan o se desconozcan relaciones de apego con los miembros considerados secundarios (Dávila, 2015).

Subsiguientemente, se logra evidenciar las dinámicas dentro del hogar, las cuales ejercen gran influencia en la forma en la que los niños y niñas van construyendo y categorizando sus niveles de apego con las figuras familiares; la poca interacción de los padres hacia los hijos o donde son expuestos a situaciones de maltrato producto de la baja cohesión familiar influyen en la calidad de afecto que pueden tener hacia sus padres (Mikulincer \& Florian, 1999; Dávila, 2015).

Por consiguiente, la percepción que tenga el niño de su familia, durante los primeros años de su vida denota un carácter fundamental, puesto que sus primeras relaciones marcarán la pauta de su forma de comprender el mundo; sin embargo y dado el carácter multicausal de las familias, dichas percepciones no son totalitarias, es decir, con el paso del tiempo la experiencia de los niños y niñas empieza a sumar para identificar y permitir mejores concepciones que posean sobre sus padres y su hogar.

\section{Conclusiones}

Se concluye que la concepción de familia y dinámica familiar de los niños de cuatro años, está basado en sus propias percepciones relacionadas con el estilo de apego y crianza que poseen en relación con aquellas personas que han sido mayormente significativas para ellos, compartiendo estrechas relaciones y apoyando su proceso de desarrollo integral, así mismo se concluye que la dinámica y la organización del núcleo familiar son factores directamente proporcionales y determinantes a la hora de que el niño elabore una construcción positiva de su hogar y sus familiares.

\section{REFERENCIAS}

Abril, A. y Peinado, M. (2018). Nuevos horizontes familiares: Una reflexión en la formación inicial del profesorado. Profesorado. Revista de Currículum $y$ Formación del Profesorado, 22(1), 159-176. 
Acevedo, L. (2011). El concepto de familia hoy. Franciscanun. Revista de las ciencias del espíritu, (53)156, 149170.

Alegre, A. (2015). ¿Qué es la familia? La percepción de la familia en los niños de 5 años. [Tesis de pregrado]. Universitat Jaume I, Castellón, España.

Anyan S. y Pryor, J. (2002). What is in a family? Adolescent perceptions. Children and Society (16)5, 1-12. https:// doi.org/10.1002/chi.716

Bernete, F. (2013). Análisis de contenido. En, A. L. Marín y A. Noboa (Coords.), Conocer lo social: estrategias y técnicas de construcción $y$ análisis de datos (pp. 222-262). Madrid: Universidad Complutense de Madrid.

Casal, J. y Mateu, E. (2003). Tipos de muestreo. Revista de Epidemiología Medica Prev, 1(1), 3-7.

Cuenya, L. y Ruetti, E. (2010). Controversias epistemológicas y metodológicas entre el paradigma cualitativo y cuantitativo en psicología. Revista Colombiana de Psicología, 19(2) 271277

Dávila, Y. (2015). La influencia de la familia en el desarrollo del apego. Anales. Revista de la Universidad de Cuenca, 57. 121-130.

Díaz-Bravo, L., Torruco-García, U., Martínez-Hernández, M. y Varela-Ruiz, M. (2013). La entrevista, recurso flexible y dinámico. Investigación en educación médica, 2(7), 162-167.

Espitia, R. y Montes, M. (2009). Influencia de la familia en el proceso educativo de los menores del barrio Costa Azul de Sincelejo. Investigación y desarrollo, 17(1), 84-105.
Ferrel, F., Thomas, J., Solano, A., Redondo, E. \& Ferrel, L. (2014). Bienestar Psicológico en Profesores de una Universidad Privada del Distrito de Santa Marta. Cultura, Educación y Sociedad, 5(2), 61-76. Disponible en https://revistascientificas.cuc.edu.co/ culturaeducacionysociedad/article/ view/885/pdf_118

Gallego, A. (2012). Recuperación crítica de los conceptos de familia, dinámica familiar y sus características. Revista Virtual Universidad Católica del Norte, 1(35), 326-345.

Gómez, J. M. (2012). El grupo focal y el uso de viñetas en la investigación con niños. Focal groups and vignettes in research with children. Empiria. Revista de metodología de ciencias sociales, (24), 45-66.

Hernández, R., Fernández, C. y Babtista, P. (2014). Metodología de la investigación. 6 ed. México, D.F.: McGrawHill.

Infante, A. y Martínez, J. (2016). Concepciones sobre la crianza: el pensamiento de madres y padres de familia. Liberabit, 22(1), 31-41.

Jaramillo, L. (2007). Concepción de infancia. Zona próxima: revista del Instituto de Estudios Superiores en Educación, (8), 108-123.

López, G. y Guiamaro, Y. (2016). El rol de la familia en los procesos de educación y desarrollo humano de los niños y niñas. Ixaya. Revista Universitaria de Desarrollo Social, (10), 31-55.

Loreto, F. A. y Pinilla, I. (2017). Enfoques metodológicos en la investigación educativa: Método empírico, cualitativo y fenomenológico. Revista Guayana Virtual, 1(1). 26-35. 
Marín, F (2012). Investigación Científica. Una Visión Integrada e interdisciplinaria. Maracaibo: Ediciones del Vicerrectorado Académico de la Universidad del Zulia. Maracaibo.

Martínez, J. (2011). Métodos de investigación cualitativa. Silogismo, 8, 1-33.

Mena, M. \& Huneeus, M. (2017). Convivencia Escolar para el aprendizaje y buen trato de todos: Hacia una mejor comprensión del concepto. Cultura Educación y Sociedad, 8(2), 9-20. https://doi.org/10.17981/cultedusoc.8.2.2017.01

Miller, K. E. (2015). Dear Critics: Addressing Concerns and Justifying the Benefits of Photography as a Research Method. Forum: Qualitative Social Research, 16(3), 1-17. http:// dx.doi.org/10.17169/fqs-16.3.2434

Mikulincer, M. \& Florian, B. (1999). The Association between Parental Reports of Attachment Style and Family Dynamics, and Offspring's Reports of Adult Attachment Style. Family Process, 38(1), 243-257. http://dx.doi.org/10.1111/j.15455300.1999.00243.x

Moscoso, L. F. y Díaz, L. P. (2017). Aspectos éticos en la investigación cualitativa con niños. Revista Latinoamericana de Bioética, 18(1), 51-67. https://doi. org/10.18359/rlbi.2955

Oliva, E. y Villa, V. J. (2014). Hacia un concepto interdisciplinario de la familia en la globalización. Justicia Juris, 10(1), 11-20.

Otzen, T. y Manterola, C. (2017). Técnicas de muestro sobre una población a estudio. International Journal of Morphology, 35(1), 227-232. http://dx.doi.org/10.4067/S071795022017000100037
Páez-Martínez, R. M. (2016). ¿Des-víos de la familia en la formación de los hijos e hijas? Nuevos perfiles, funciones constantes. Revista Latinoamericana de Ciencias Sociales, Niñez y Juventud, 14(1), 261-272. https://doi.org/10. 11600/1692715x.14117260215

Rigg, A. y Pryor, J. (2007). Children's Perceptions of Families: What Do They Really Think? Children \& Society, 21, 17-30. https://doi.org/10.1111/j.10990860.2006.00028.x

Rodrigo, M. y Correa, N. (2003). Representación y procesos cognitivos: esquemas y modelos mentales. En J. Palacios, A. Marchesi \& C. Coll (Coords.), Psicología y Educación (pp. 117-135). Madrid: Alianza Editorial S.A.

Rodrigo, M. J. y Palacios, J. (2012). Familia y desarrollo humano. Madrid: Alianza.

Salgar, C. A. (2017). Concepto de familia: cambios estructurales y conceptuales desde la interdisciplinariedad, las teorías de género y la psicología. Una revisión documentada. [Tesis de pregrado]. Fundación Universitaria Los Libertadores, Bogotá, D.C., Colombia.

Salkind, N. J. (1998). Métodos de investigación. México, D.F.: Prentice Hall.

Sánchez, C. (2012). Significado psicológico de familia, papá y mamá en adolescentes. Psicología Iberoamericana, 20(1). 2-12.

San Martín, D. (2014). Teoría fundamentada y Atlas.ti: recursos metodológicos para la investigación educativa. Redie, Revista electrónica de investigación educativa, 16(1), 104-122.

Triana, A., Ávila, L. y Malagón, A. (2010). Patrones de crianza y cuidado de niños y niñas en Boyacá. Revista Latinoamericana de Ciencias Sociales, Niñez y Juventud, 8(2), 933-945. 
Parra, Y. (2010). Representación social del conflicto armado colombiano en niños y niñas de un colegio adscrito a la Policía Nacional. Universitas Psychologica, 10(3), 775-778.

Perinat, A. (2007). Psicología del desarrollo. Un enfoque sistémico. 3 ed. Barcelona: Editorial UOC.

Piaget, J. e Inhelder, B. (2007). Psicología de niño. Madrid: Morata.

República de Colombia. Congreso de la República. (6 de septiembre de 2006). Por la cual se reglamenta el ejercicio de la profesión de Psicología, se dicta el Código Deontológico y Bioético y otras disposiciones. [Ley 1990]. Diario Oficial: 46.383 .

Varguillas, C. (2006). El uso de Atlas. Ti y la creatividad del investigador en el análisis cualitativo de contenido Upel. Instituto pedagógico rural el Mácaro. Laurus, Revista de educación, 12(2), 73-87.

Vergara, A., Peña, M., Chávez, P. y Vergara, E. (2015). Los niños como sujetos sociales: El aporte de los Nuevos Estudios Sociales de la infancia y el análisis crítico del discurso. Psicoperspectivas: Individuo y Sociedad, 14(1), 55-65. 